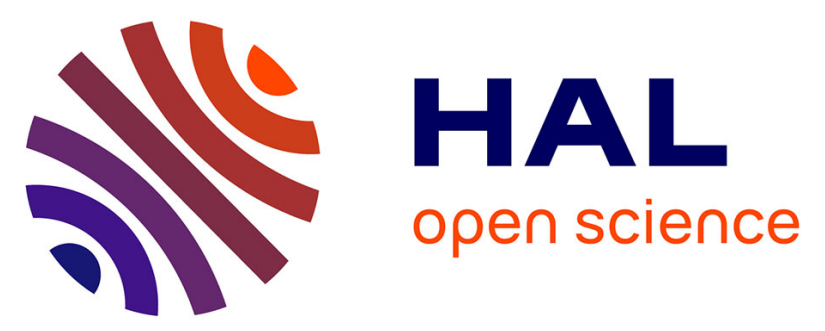

\title{
Photosensitized Degradation of Model Lipid Membranes based on 1-palmitoyl-2-oleyl-phosphatidylcholine (POPC)
}

\author{
A V Shokurov, D. N Novak, M A Grin, C. Grauby-Heywang, T. \\ Cohen-Bouhacina, A V Zaytseva, V. V Arslanov, S. L Selektor
}

\section{To cite this version:}

A V Shokurov, D. N Novak, M A Grin, C. Grauby-Heywang, T. Cohen-Bouhacina, et al.. Photosensitized Degradation of Model Lipid Membranes based on 1-palmitoyl-2-oleyl-phosphatidylcholine (POPC). Protection of Metals and Physical Chemistry of Surfaces, 2018, 54 (1), pp.19-26. 10.1134/S2070205118010124. hal-01844823

\section{HAL Id: hal-01844823 \\ https://hal.science/hal-01844823}

Submitted on 19 Jul 2018

HAL is a multi-disciplinary open access archive for the deposit and dissemination of scientific research documents, whether they are published or not. The documents may come from teaching and research institutions in France or abroad, or from public or private research centers.
L'archive ouverte pluridisciplinaire HAL, est destinée au dépôt et à la diffusion de documents scientifiques de niveau recherche, publiés ou non, émanant des établissements d'enseignement et de recherche français ou étrangers, des laboratoires publics ou privés.

\section{(2)(1) $\$$}

Distributed under a Creative Commons Attribution - NonCommercial - ShareAlikel 4.0 


\title{
Photosensitized Degradation of Model Lipid Membranes based on 1-palmitoyl-2-oleyl-phosphatidylcholine (POPC) ${ }^{1}$
}

\author{
A. V. Shokurov ${ }^{a}$, D. N. Novak ${ }^{b}$, M. A. Grin ${ }^{b}$, C. Grauby-Heywang ${ }^{c}$, T. Cohen-Bouhacina ${ }^{c}$, \\ A. V. Zaytseva ${ }^{a}$, V. V. Arslanov ${ }^{a}$, and S. L. Selektor ${ }^{a, *}$ \\ ${ }^{a}$ Frumkin Institute of Physical Chemistry and Electrochemistry of Russian Academy of Sciences, Moscow, 119071 Russia \\ ${ }^{b}$ Moscow Technological University, Moscow, 119571 Russia \\ ${ }^{c}$ Laboratoire Ondes et Matière d'Aquitaine (LOMA), Université de Bordeaux, \\ UMR-CNRS 5798, Talence Cedex, 33405 France \\ *e-mail:sofs@list.ru
}

\begin{abstract}
In this work, we study the interaction of a well-known photosensitizer, MePha, with models of biological membrane (Langmuir monolayers and Langmuir-Schaeffer planar bilayers) based on one of the most important natural lipid, POPC, for the subsequent investigation of photodestruction processes in a context of photodynamic therapy treatment. Changes of macroscopic properties and morphology of POPC/MePha model membranes upon irradiation by visible light are recorded by means of contact angle measurements and atomic force microscopy, demonstrating clearly the possibility to use these methods for the study of photodestruction of artificial lipid membranes on solid substrates, but also for a comparative study of the efficiency of novel photosensitizers.
\end{abstract}

\section{INTRODUCTION}

Photodynamic therapy (PDT) of oncological diseases is one of the most promising and widely studied fields of medical chemistry. PDT is based on the penetration of a photosensitizer (PS) in cells, followed by its photo-irradiation and the formation of free-radical oxygen metabolites, able to induce irreversible photodamages and to oxidize biomolecules, and consequently to destroy tumor and its surrounding vasculature [1]. However, despite the large number of publications devoted to the development of new PDT drugs, detailed mechanism of the effect of active forms of oxygen on cell organelles and membranes is still relatively unknown.

Experimental studies in this field are carried out either on living cells [2-4] or on systems modelling the cell components, particularly their lipid membranes [5-13]. One of the key approaches used in this regard is the use of liposomes, PS being introduced during the bilayer formation process or after by insertion [7$9,13,14]$. Afterwards, upon irradiation by light with the required wavelength, PS starts generating active oxygen forms, causing membrane damages which can be observed by various physico-chemical methods. Another approach for modelling of PDT processes is based on black lipid membranes including PS, formed

\footnotetext{
${ }^{1}$ The article was translated by the authors.
}

at the level of a small hole drilled in a flat substrate and separating two aqueous phases [15-17]. In this case, changes in membrane permeability or electrical resistance can be studied.

From this standpoint, lipid bilayers formed on solid supports are especially interesting. In these systems, lipids are either tethered to the substrate [18-22], or stabilized on it due to strong adhesive interactions [19, 2326]. In this regard, it can be deemed most efficient to employ the Langmuir-Blodgett (LB) and LangmuirSchaeffer (LS) methods, which make possible to form and to study lipid bilayers, stable if they are kept in contact with an aqueous phase, with various inclusions, on virtually any solid hydrophilic supports [19, 20, 27-35].

Thus, in the present work we aim to develop a method to form model lipid bilayers from Langmuir monolayers based on 1-palmitoyl-2-oleyl-phosphatidylcholine (POPC) and to study the process of their photodestruction in the presence of pheophorbide $a$ methyl ether (MePha) by means of combined atomic force microscopy (AFM) and wetting angle measurements. Moreover, the aims of the work include estimation of the possibility to investigate the process of bilayer photodestruction in such a way, before widening it to other PS. 


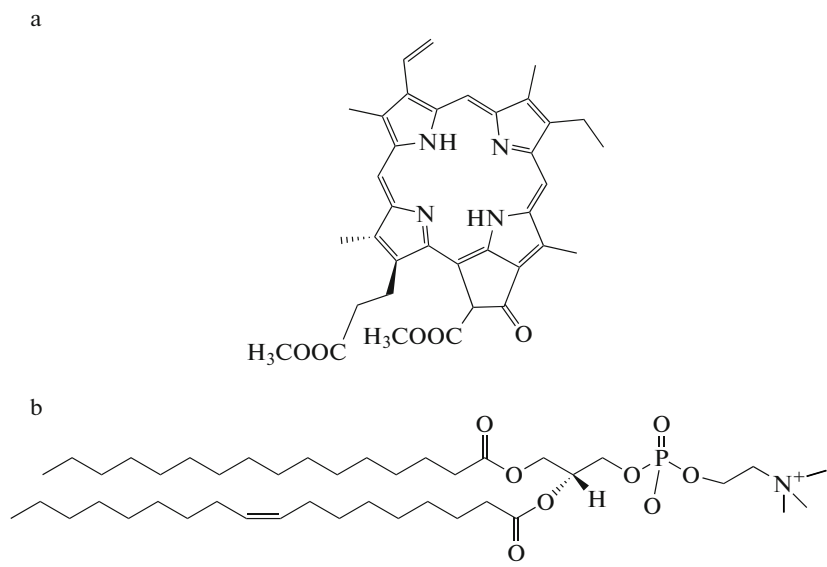

Fig. 1. Chemical structures of (a) MePha and (b) POPC.

\section{RESULTS AND DISCUSSION}

Lipid POPC (Fig. 1) was chosen as a model lipid for the formation of the monolayers and bilayers because it acts as a main structure-forming lipid in a large number of live cells, and also due to the large amount of available literature on its behavior in monoand bilayers. Moreover, as shown previously by AFM [30] this lipid can be oxidized, being thus a plausible target in PDT modeling.

MePha (Fig. 1) is a convenient model PS due to its previously demonstrated high efficiency and the fact that its properties are well-studied [36, 37].

On a first stage, we investigated monolayers of pure MePha at the air/water interface. Reproducibility of compression isotherms (Fig. 2), coherent mean molecular areas and absorbance spectra indicates that MePha forms stable monolayers at the air-water interface, with probably negligible dissolution in aqueous subphase, formation of multilayers or micellation. This fact creates positive premises for its possible use in mixed monolayers with POPC lipid.

Mean molecular area corresponding to the start of surface pressure increase (around $130 \AA^{2}$ ) was found to be significantly lesser than the expected value taking into account the planar chemical structure of MePha, suggesting that the long axis of PS in the monolayer is oriented perpendicularly relative to the subphase surface. This assumption agrees well with the MePha monolayer absorbance spectra (Fig. 3, set of curves 2), which indicate the formation of stacking aggregates: position of all spectral bands is significantly batochromically shifted (from 30 to $50 \mathrm{~nm}$ ) as compared to the absorbance spectrum of the forming solution in chloroform (Fig. 3, curve 1). Moreover, ratios of the intensities of individual components of these spectra also differ significantly and monolayer spectra intensity logically increases with surface pressure.

As it is well known, aggregated state of PS can inhibit generation of active oxygen forms [37-39].

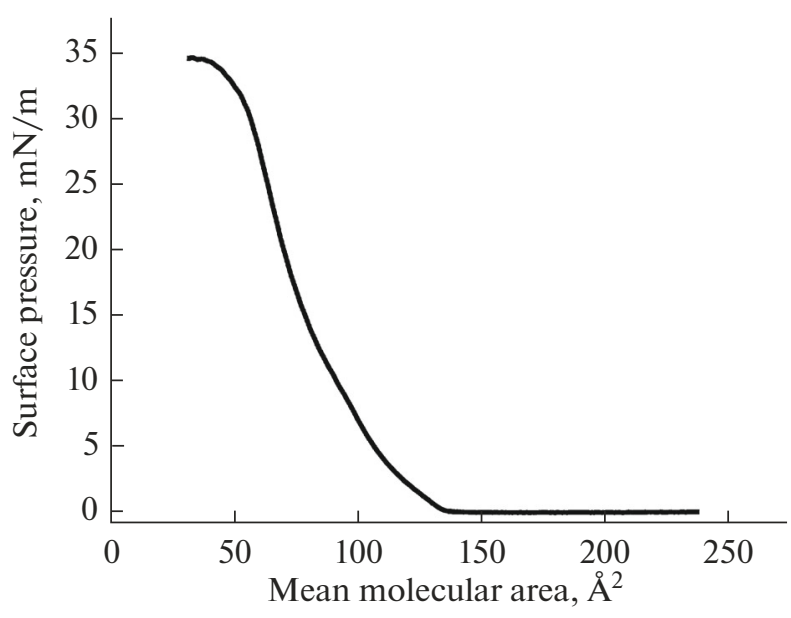

Fig. 2. Individual MePha monolayer isotherm.

One of the most efficient ways to inhibit aggregation is inclusion of PS into highly organized matrix [38], and ordered Langmuir lipid monolayers can be used in this way.

Thus, on the next stage of this work, we studied mixed POPC : MePha monolayers at various molar ratios at the air-water interface (Fig. 4). Mean molecular areas are calculated by POPC molecule taking into account the lipid concentration after the dilution of this solution by the PS one. The isotherm of pure POPC is in agreement with isotherms previously shown [35], showing that this lipid is in a liquid expanded phase state during compression. The presence of MePha at increasing ratio shifts the isotherm to higher mean molecular areas, indicating that MePha is inserted in the monolayer. The high shift compared to the mean molecular areas on pure MePha isotherm suggests that POPC favors the spreading of PS at the interface in a surface parallel orientation, avoiding aggregates at the same time. This hypothesis is supported by absorbance spectra (Fig. 5). Mean molecular areas of the start of surface pressure increase on isotherms for monolayers with ratios of POPC : MePha from $20: 1$ to $4: 1$ (Fig. 4) indicate good compatibility of the components. These results allow us to assume that POPC facilitates spreading of PS on the interface and inhibits its aggregation as well.

Indeed, spectra of PS included in such mixed monolayers (Fig. 5) significantly differ from spectra of pure MePha monolayer: first, bands appear on the whole at similar wavelengths to ones in the PS solution spectrum (a bathochromic shift of $5 \mathrm{~nm}$ is observed, probably due to changes of polarity of the environment happening upon transition from bulk to two-dimensional air/water interface); secondly intensity ratios of separate spectral bands are analogous to those observed in PS solution. At last, compression of such monolayer does not lead to any significant spectral change. All these facts indicate inhibition of MePha 


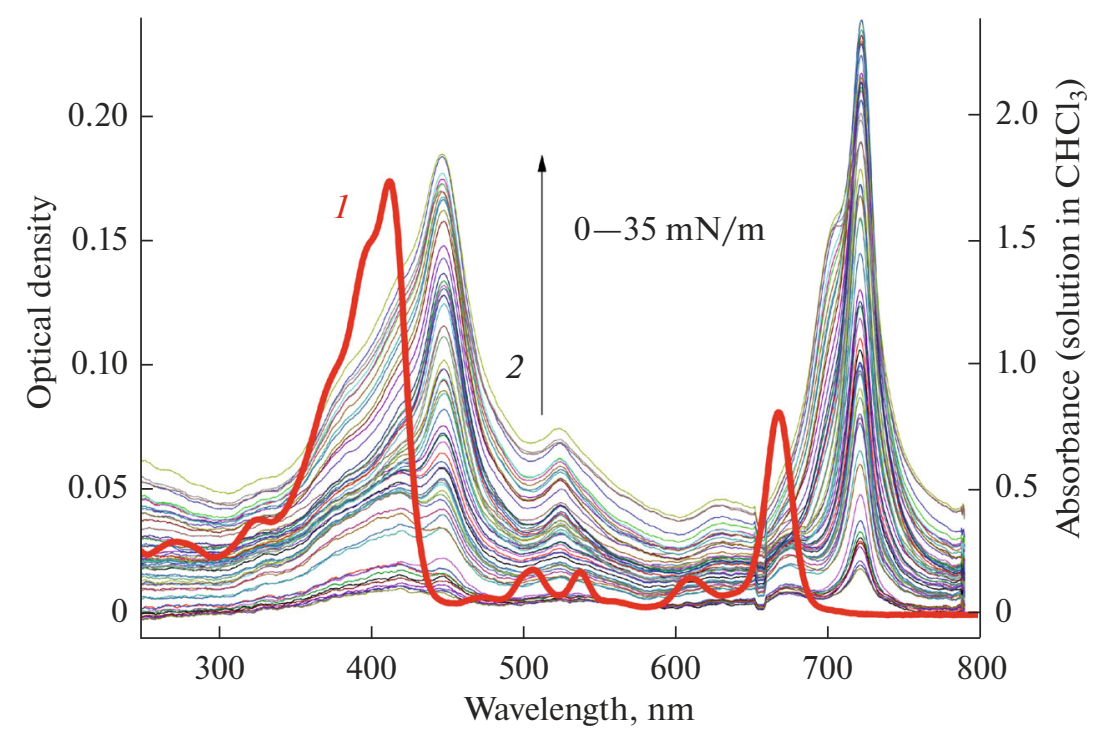

Fig. 3. Absorbance spectra of (1) MePha chloroform solution and (2) its pure monolayer during compression.

aggregation in the mixed monolayer and its predominant existence in lipid matrix in monomeric form in all the surface pressure range $(0-30 \mathrm{mN} / \mathrm{m})$.

However, the absence of aggregates does not explicitly indicate a homogenous distribution of PS in the lipid matrix. Thus, in order to determine the optimal composition of the monolayer, mixed monolayers with various POPC : MePha molar ratios were transferred onto quartz substrates by the LangmuirBlodgett-Schaeffer method. Obtained lipid bilayers containing MePha were studied using fluorescence microscopy.

Typical fluorescence images are shown on Fig. 6. They demonstrate that despite the general homogeneity of the samples (at the resolution of fluorescence microscopy), increase of MePha content up to 10 mol\% (POPC : MePha $10: 1$ ) leads to the formation of areas characterized by increased PS fluorescence intensity as compared to surrounding phase. Most probably, these areas are due to local crystallization of PS in the film. At POPC : MePha molar ratio $20: 1$ such heterogeneity is not observed. On the contrary, change of molar ratio in favor of PS (POPC : MePha $1: 2$ ) leads to significant enlargement of the areas with increased fluorescence intensity, which confirms the role of excessive concentration of PS in the process of formation of observed crystal-like defects.

Overall homogeneity of the macroscopic lipid bilayer structure containing 5 and $10 \mathrm{~mol} \%$ of PS is also confirmed by contact angle measurements: contact angles are similar in the case of pure POPC bilayers and POPC : MePha $(10: 1$ or $20: 1)$ bilayers in the absence of irradiation (Fig. 7).

In order to study the process of photoinduced degradation of the model lipid membranes containing PS, samples were exposed to irradiation by visible light in a wavelength range of 350-800 $\mathrm{nm}$ during $60-150 \mathrm{~min}$. Contact angle values of water droplets were measured at different steps of the exposure (Fig. 7). In the case of pure POPC bilayers, contact angle increases of only $1^{\circ}$ after $60 \mathrm{~min}$ of exposure, showing that the integrity of the bilayer is maintained. On the contrary in the presence of PS, contact angles increase significantly with exposure time, showing that the surface becomes more hydrophobic. This effect is probably due to the destruction of the upper layer of the lipid bilayer and the resulting uncovering of hydrophobic alkyl chains of POPC of the lower monolayer in contact with the substrate. At last, the increase of contact angle is not

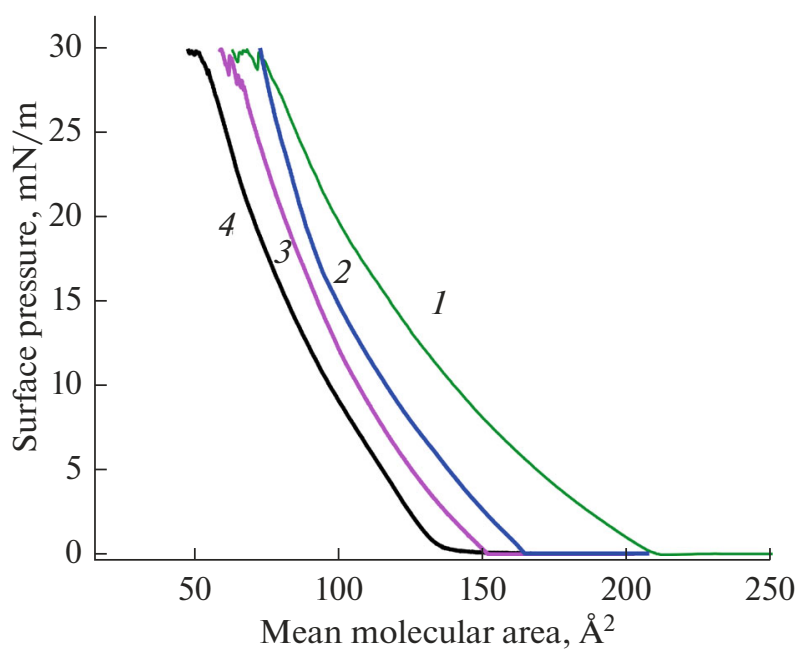

Fig. 4. Compression isotherms of POPC : MePha monolayers with molar ratios: (1) $4: 1$, (2) $10: 1$, (3) $20: 1$ (mean molecular area being calculated per POPC molecule), and (4) compression isotherm of pure POPC. 


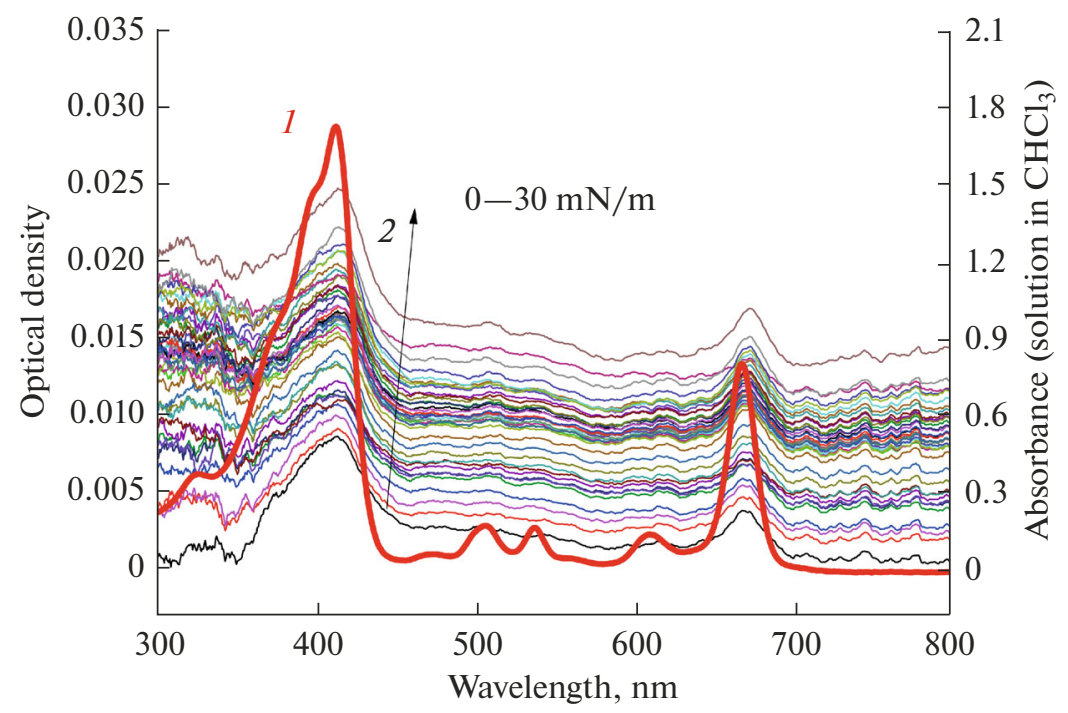

Fig. 5. Absorbance spectra of (1) MePha chloroform solution and (2) mixed POPC : MePha monolayer with a molar ratio of $10: 1$ during compression.

significantly different between bilayers containing 5 and $10 \mathrm{~mol} \%$ of PS, rising to $5^{\circ}$ and $7^{\circ}$, respectively. This could be due to the fact that bilayers containing 10 mol \% of PS contain also more aggregates, which can inhibit generation of active oxygen forms, as previously mentioned [37-39]. Finally, these results support the correlation between the PS concentration and the photodestruction of POPC bilayer.

AFM was used for a further detailed study of morphological changes occurring in lipid bilayers upon irradiation. Figure 8 shows first typical AFM images obtained for control POPC bilayer during irradiation by visible light in the $0-150$ min range. In the absence of exposure, height images show the presence of small "spots" regularly distributed. The contrast inversion in corresponding phase images shows that these areas are also more dissipative, and thus more "soft". Height profiles (Fig. 9a) confirm the presence of areas higher than the surrounding phase, with a step of $0.2-$ $0.3 \mathrm{~nm}$. This value, clearly lower than the POPC size, suggests that these spots are not due to areas organized in bilayer with a surrounding phase organized in monolayer. After irradiation, AFM images and height
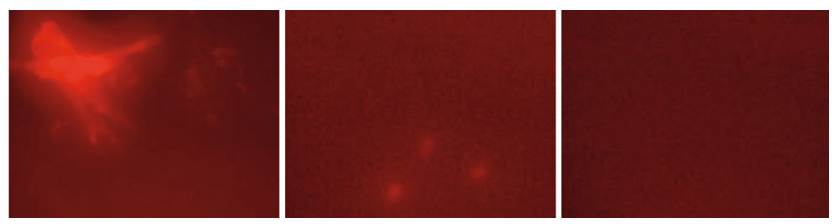

Fig. 6. Typical images $(500 \times 400 \mathrm{~nm})$, obtained by fluorescence microscopy of mixed planar bilayers with variable POPC : MePha ratios (from left to right: $1: 2,10: 1,20: 1$ ). Excitation and emission are in the wavelength ranges of at $335-448 \mathrm{~nm}$ and $600-800 \mathrm{~nm}$, respectively. profiles demonstrate that irradiation of POPC bilayers does not lead to any significant changes of the surface (Fig. 8).

In the case of POPC : MePha bilayers in the absence of exposure (Fig. 10), AFM height images are homogenous, but phase ones reveal the presence of domains regularly distributed, some of them having larger dimensions than those previously observed in the absence of PS. After $60 \mathrm{~min}$ of exposure to light, these domains become observable with a "spongy" texture in height image (Fig. 9b, curve 2). Height profiles show that, these "spongy" domains are higher of around $1 \mathrm{~nm}$. On corresponding phase images,

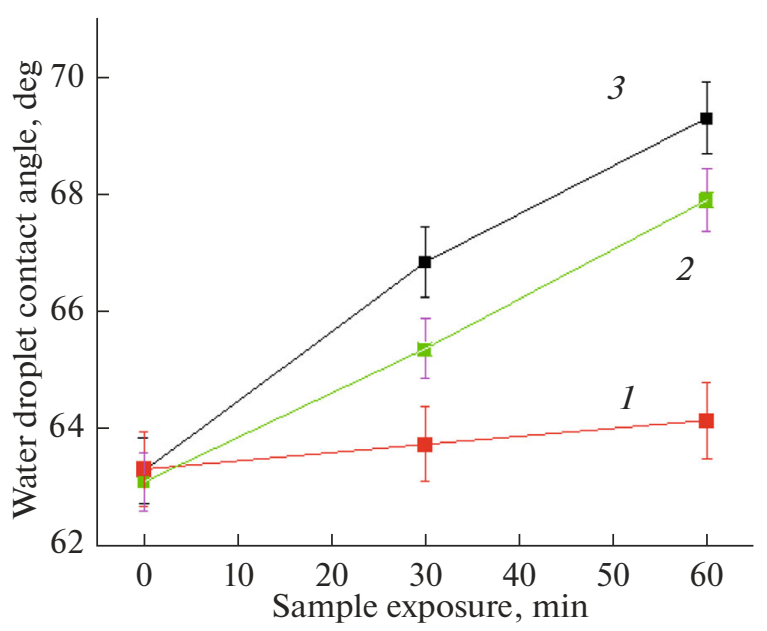

Fig. 7. Dependence of contact angles of water droplets deposited onto POPC : MePha bilayers upon enduring irradiation by visible light: (1) control POPC bilayer, and mixed bilayers with POPC : MePha (2) $20: 1$ and (3) 10 : 1 molar ratios. 


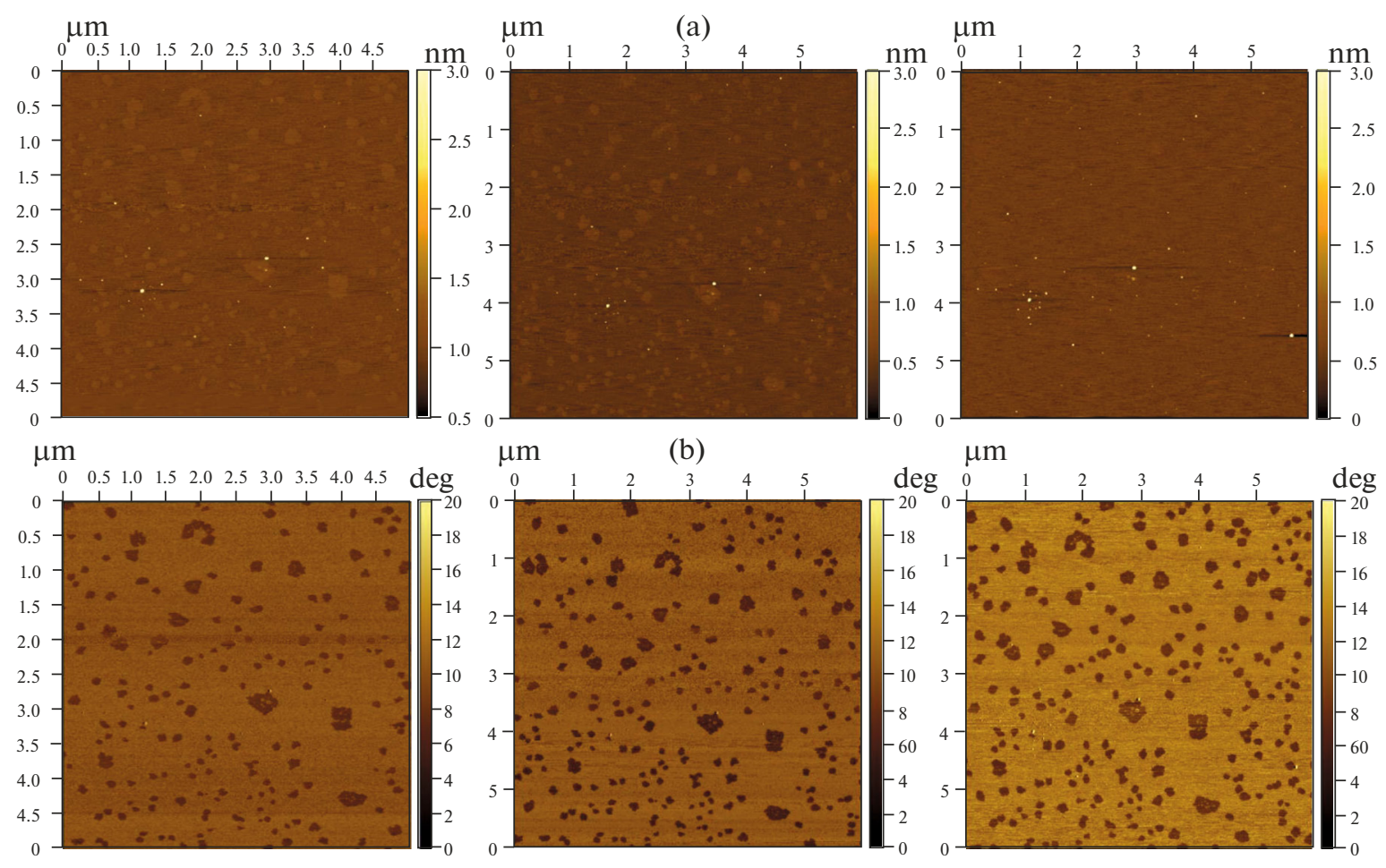

Fig. 8. AFM images of the control POPC bilayer without PS: (a) height images, (b) phase images. From left to right: 0 , 60, and $150 \mathrm{~min}$ of exposure to visible light, respectively.

(a)

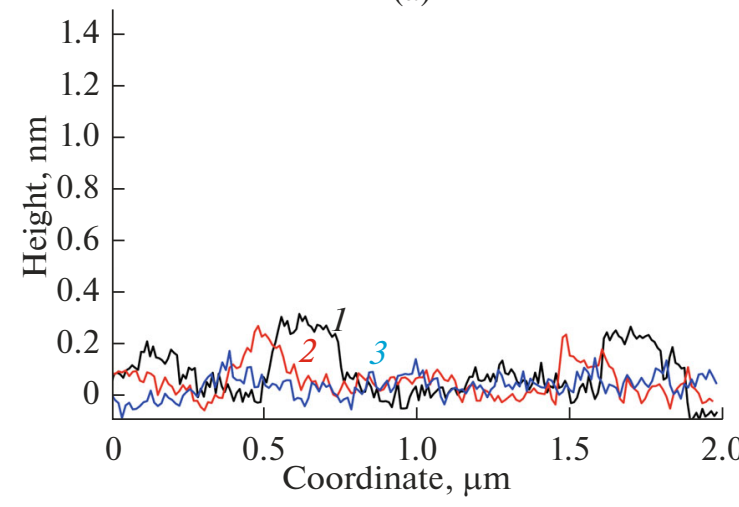

(b)

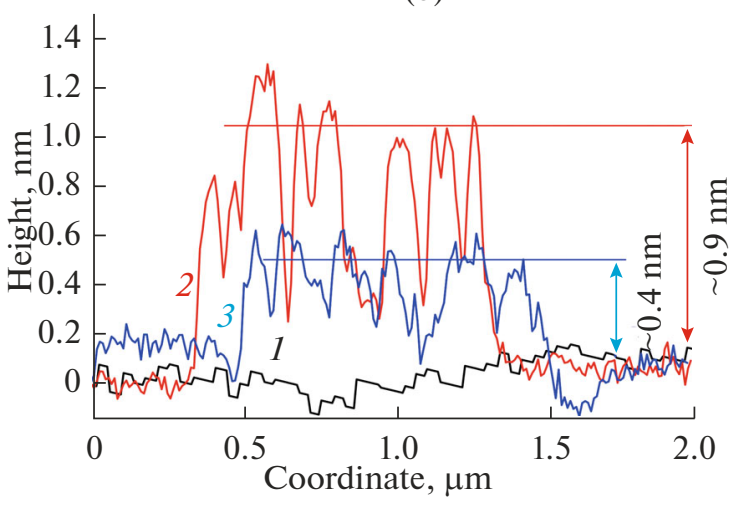

Fig. 9. Typical height profiles of (a) pure POPC bilayer and (b) POPC bilayer containing 10 mol\% of MePha (1) before irradiation, and after (2) 60 and (3) 150 min of exposure to visible light.

domains are still visible but with an inverted contrast as compared to the previous phase images. This suggests that domains after exposure are more rigid than the surrounding lipid phase. Additionally, photodestruction of the bilayer occurs in an analogous way on the whole area of the film, manifesting through the appearance and the increase of number of small dark spots on the phase images, which confirms relatively uniform distribution of the PS in bilayer.

At last, surprisingly, these domains seem to disappear after $150 \mathrm{~min}$ of exposure to light, height profiles showing a decrease of the steps. Moreover, they show that the degradation process has a quite complex nature. The presence of PS combined with light exposure could lead, in a first step, to the formation of degraded products of POPC, such as oxidized derivatives. Indeed, it has been shown that air oxygen is able to cause POPC oxidation into planar monolayers. The higher polarity of oxidized chains causes their reversal, raising the molecule above the plane of the monolayer and leading to a local increase of $0.8 \mathrm{~nm}$ [30]. This value is in agreement with the value of $1 \mathrm{~nm}$ observed 

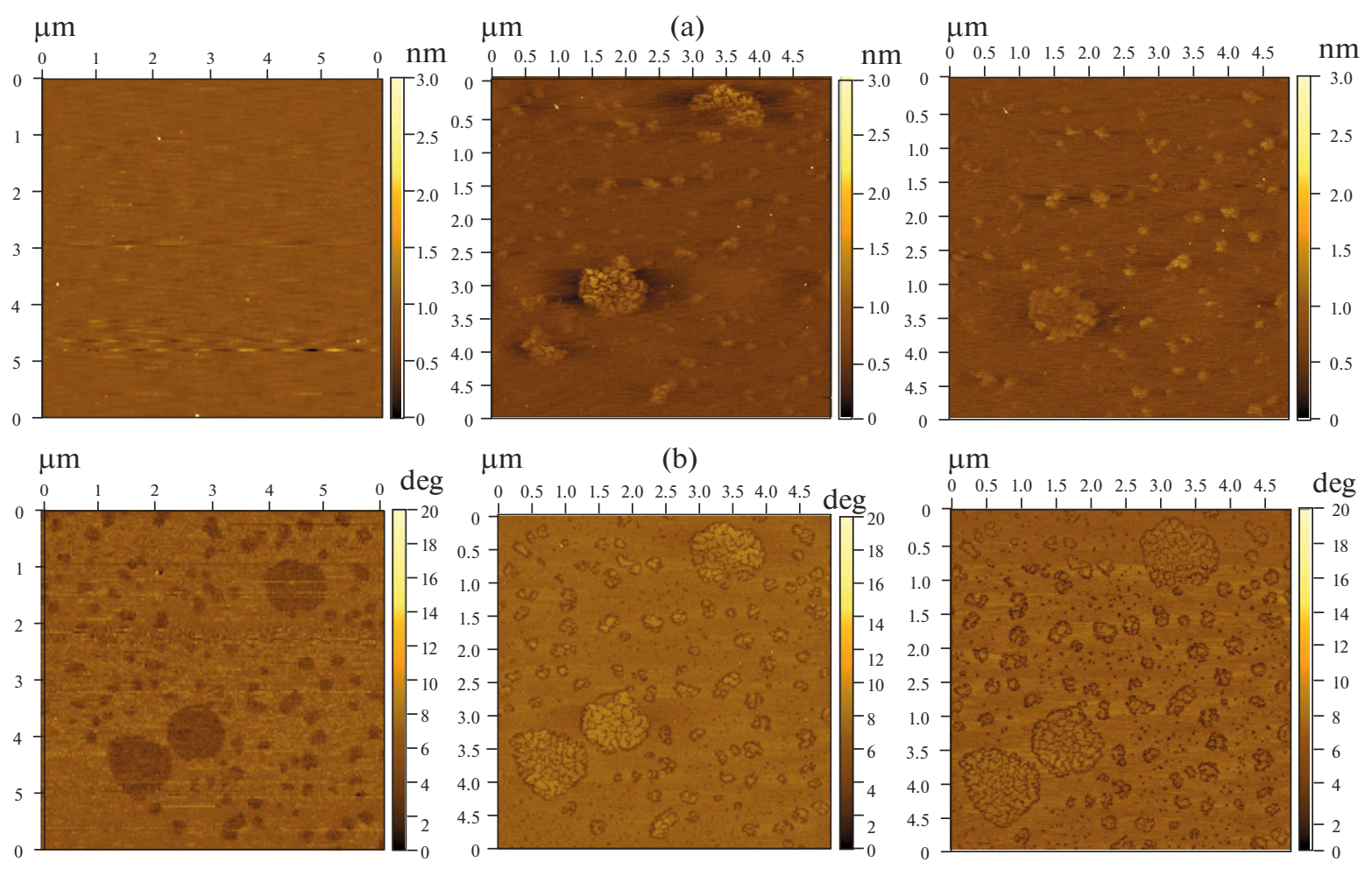

Fig. 10. AFM images of a mixed POPC : MePha $10: 1$ bilayer. (a) Height images, (b) phase images. From left to right: 0 , 60, and 150 minutes of exposure to visible light, respectively.

in the height profile of POPC : MePha bilayers exposed to light during $60 \mathrm{~min}$ (Fig. 9b, curve 2). A further exposure would lead to a re-organization of molecules in the plane of the bilayer and further molecular degradation.

\section{CONCLUSIONS}

Photodestruction of model lipid bilayer based on POPC and MePha photosensitizer by active oxygen forms was observed upon irradiation with visible light at wavelengths of $350-800 \mathrm{~nm}$. The composition of mixed lipid bilayer was optimized based on surface pressure measurements, contact angle measurement and fluorescence microscopy. It was shown in particular that the value of contact angle of water droplets on the surface of these bilayers reflects well the process of their photodestruction induced by MePha PS. Changes of morphology of mixed planar bilayers upon light exposure was also studied using AFM, revealing a likely complex process involving chemical degradation and reorganization of lipids and PS.

The possibility to employ the proposed approach to study the mechanism of sensitized photodestruction of lipid membranes and comparative evaluation of the effectiveness of photosensitizers developed for photodynamic therapy is demonstrated.

\section{EXPERIMENTAL}

Methyl ether of pheophorbide $a$ (MePha) is a chlorophyll $a$ derivative obtained according to a known procedure [40].

Lipid POPC (1-Palmitoyl-2-oleoylphosphatidylcholine) was acquired from Sigma-Aldrich ( $\geq 95.5 \%$ (GC), $\geq 98 \%$ (TLC)).

Langmuir mini-trough from KSV (Finland) with a surface area of $273.0 \mathrm{~cm}^{2}$ was used for surface pressure measurements. The trough is made of Teflon whereas barriers are made of hydrophilic polymer polyacetal. Compression isotherms were recorded using an automated Langmuir balance and a platinum Wilhelmy plate. Before experiments Langmuir trough was cleaned by acetone, chloroform, and distilled water, and polyacetal barriers by ethanol and distilled water. Monolayers were spread on ultrapure water from solutions at $1 \mathrm{mM}$ in chloroform for PS and in chloroform/ethanol (v/v) for POPC. All solvents were HPLC grade. Experiments were performed at $25^{\circ} \mathrm{C}$.

Model lipid bilayers (pure POPC or POPC : PS ones) were formed by Langmuir-Blodgett-Schaeffer technique onto quartz or mica substrates. At first stage, vertical transfer according to LangmuirBlodgett technique was carried out at a constant surface pressure of $20 \mathrm{mN} / \mathrm{m}$, which provides orientation of hydrophobic parts of the molecules outwards from the substrate. Then, according to Langmuir-Schaef- 
fer method, a second layer was transferred onto horizontally oriented substrate bearing the first singlelayer film, resulting in the contact of hydrophobic parts of the lipids between the two layers.

UV-vis absorbance spectra of solutions were recorded in the range of 190-900 nm using a UV 2450 PC Shimadzu (Japan) spectrophotometer.

Absorbance spectra of monolayers at the air/water interface during compression were obtained using an AvaSpec-2048 (Netherlands) fiber optic spectrometer. Our device allows to record the absorbance spectra in situ directly upon compression of the monolayer, according to the technique described previously [41].

Fluorescence images of POPC : PS planar bilayers transferred on quartz substrates were obtained using an device including a LOMO MIKMED-2 microscope equipped with mercury lamps (DRS 100, HBO $100 \mathrm{~W} / 2$ ) and light filter holders for excitation (FS-1-8, wavelength range of 335-448 $\mathrm{nm}$ ) and emission (KS-11 wavelength range of 600-800 $\mathrm{nm}$ ), and an Olympus XC50 camera. Integration time usually amounted from 10 to $25 \mathrm{~s}$. No less than 3 images in 7 different places were obtained for each sample. Due to high numerical aperture of the objectives, resolution of the device was in the range of $0.4-0.6 \mu \mathrm{m}$.

Contact angle values were determined using the Contact Angles Measurement System-101 from KSV (Finland). The device is equipped with a high resolution optical camera, a high intensity red lamp and an objective stage. Droplets of distilled water were deposited onto different places of the sample and average wetting angle values were calculated using KSVCam100 software (4-5 measurements per sample).

Bilayers for AFM studies were transferred onto high quality and freshly cleaved mica. These studies were conducted on a Multimode V (Veeco, USA) microscope, equipped with a Nanoscope IIIa controller and TESP brand AFM tips (standard geometry, needle height $10 \mu \mathrm{m}$, point radius $5 \mathrm{~nm}$ ). All measurements were done in tapping mode. Several images through all the sample area were performed. Processing of the AFM data and height profile acquirement were done using Gwyddion 2.45 software package.

\section{ACKNOWLEDGMENTS}

The present work was financially supported by Russian Foundation for Basic research, (project no. 17-53-150013 CNRS a) and by French Centre National de la Recherche Scientifique (joint research project no. 1520). Experimental studies were performed using the equipment of CKP FMI IPCE RAS.

\section{REFERENCES}

1. MacDonald, I.J. and Dougherty, T.J., J. Porphyrins Phthalocyanines, 2001, vol. 5, no. 2, pp. 105-129.
2. Moan, J., Pettersen, E.O., and Christensen, T., Br. J. Cancer, 1979, vol. 39, no. 4, pp. 398-407.

3. Carraro, C. and Pathak, M.A., J. Invest. Dermatol., 1988, vol. 90, no. 3, pp. 267-275.

4. Roberts, W.G., Liaw, L.-H.L., and Berns, M.W., Lasers Surg. Med., 1989, vol. 9, no. 2, pp. 102-108.

5. Desroches, M.C., Kasselouri, A., Meyniel, M., Fontaine, P., Goldmann, M., Prognon, P., Maillard, P., and Rosilio, V., Langmuir, 2004, vol. 20, no. 26, pp. 11698-11705.

6. Gravier, J., Korchowiec, B., Schneider, R., and Rogalska, E., Chem. Phys. Lipids, 2009, vol. 158, no. 2, pp. 102-109.

7. Hoebeke, M., J. Photochem. Photobiol., B, 1995, vol. 28, no. 3, pp. 189-196.

8. Bonneau, S., Morlière, P., and Brault, D., Biochem. Pharmacol., 2004, vol. 68, no. 7, pp. 1443-1452.

9. Makky, A., Michel, J.P., Maillard, P., and Rosilio, V., Biochim. Biophys. Acta, Biomembr., 2011, vol. 1808, no. 3, pp. 656-666.

10. Cordeiro, R.M., Miotto, R., and Baptista, M.S., J. Phys. Chem. B, 2012, vol. 116, no. 50, pp. 14618-14627.

11. Postigo, F., Mora, M., De Madariaga, M.A., Nonell, S., and Sagristá, M.L., Int. J. Pharm., 2004, vol. 278, no. 2, pp. 239-254.

12. Kerdous, R., Heuvingh, J., and Bonneau, S., Biochim. Biophys. Acta, Biomembr., 2011, vol. 1808, no. 12, pp. 2965-2972.

13. Chowdhary, R.K., Green, C.A., and Morgan, C.G., Photochem. Photobiol., 1993, vol. 58, no. 3, pp. 362366.

14. Chatterjee, S.N. and Agarwal, S., Free Radicals Biol. Med., 1988, vol. 4, no. 1, pp. 51-72.

15. Sokolov, V.S., Gavrilchik, A.N., Kulagina, A.O., Meshkov, I.N., Pohl, P., and Gorbunova, Y.G., J. Photochem. Photobiol., B, 2016, vol. 161, pp. 162-169.

16. Naumowicz, M., Petelska, A.D., and Figaszewski, Z., Electrochim. Acta, 2005, vol. 50, no. 10, pp. 2155-2161.

17. Stratton, S.P. and Liebler, D.C., Biochemistry, 1997, vol. 36, no. 42, pp. 12911-12920.

18. Cho, N.-J., Frank, C.W., Kasemo, B., and Höök, F., Nat. Protoc., 2010, vol. 5, no. 6, pp. 1096-1106.

19. Richter, R.P., Escarpit, R.R., and Cedex, P., Langmuir, 2006, vol. 22, no. 12, pp. 3497-3505.

20. Tamm, L.K. and McConnell, H.M., Biophys. J., 1985, vol. 47, no. 1, pp. 105-113.

21. Giess, F., Friedrich, M.G., Heberle, J., Naumann, R.L., and Knoll, W., Biophys. J., 2004, vol. 87, no. 5, pp. 3213-3220.

22. Naumann, R., Schiller, S.M., Giess, F., Grohe, B., Hartman, K.B., Kärcher, I., Köper, I., Lübben, J., Vasilev, K., and Knoll, W., Langmuir, 2003, vol. 19, no. 13 , pp. 5435-5443.

23. Puu, G. and Gustafson, I., Biochim. Biophys. Acta, 1997, vol. 1327, no. 2, pp. 149-161.

24. Keller, C.A. and Kasemo, B., Biophys. J., 1998, vol. 75, no. 3, pp. 1397-1402.

25. Dufrêne, Y.F. and Lee, G.U., Biochim. Biophys. Acta, 2000, vol. 1509, nos. 1-2, pp. 14-41. 
26. Tamm, L.K. and McConnell, H.M., Biophys. J., 1985, vol. 47, no. 1, pp. 105-113.

27. Osborn, T.D. and Yager, P., Biophys. J., 1995, vol. 68, no. 4, pp. 1364-1373.

28. Girard-Egrot, A.P. and Blum, L.J., in Nanobiotechnology of Biomimetic Membranes, Martin, D.K., Ed., Springer Science \& Business Media, 2007, Ch. 2.

29. Gust, D., Moore, T.A., Moore, A.L., Luttrull, D.K., DeGraziano, J.M., Boldt, N.J., Van der Auweraer, M., and De Schryver, F.C., Langmuir, 1991, vol. 7, no. 7, pp. 1483-1490.

30. Faye, N.R., Moroté, F., Grauby-Heywang, C., and Cohen-Bouhacina, T., Int. J. Nanotechnol., 2013, vol. 10, nos. 5/6/7, pp. 390-403.

31. Conboy, J.C., Liu, S., O’Brien, D.F., and Saavedra, S.S., Biomacromolecules, 2003, vol. 4, no. 3, pp. 841-849.

32. Dufrene, Y.F., Barger, W.R., Green, J.-B.D., and Lee, G.U., Langmuir, 1997, vol. 13, no. 18, pp. 47794784.

33. Grauby-Heywang, C., Moroté, F., Mathelié-Guinlet, M., Gammoudi, I., Faye, N.R., and Cohen-Bouhacina, T., Chem. Phys. Lipids, 2016, vol. 200, pp. 74-82.
34. Hąc-Wydro, K. and Dynarowicz-Lątka, P., Ann. Univ. Mariae Curie-Sklodowska, Sect. AA: Chem., 2008, vol. 63, pp. 47-60.

35. Grauby-Heywang, C. and Turlet, J.-M., Chem. Phys. Lipids, 2006, vol. 139, no. 1, pp. 68-76.

36. Grin, M.A., Mironov, A.F., and Shtil, A.A., Anti-Cancer Agents Med. Chem., 2008, vol. 8, no. 6, pp. 683-697.

37. Pandey, R.K., Bellnier, D.A., Smith, K.M., and Dougherty, T.J., Photochem. Photobiol., 1991, vol. 53, no. 1, pp. 65-72.

38. Gottfried, V., Peled, D., Winkelman, J.W., and Kimel, S., Photochem. Photobiol., 1988, vol. 48, no. 2, pp. 157163.

39. Lapkina, L.A., Gorbunova, Yu.G., Gil, D.O., Ivanov, V.K., Konstantinov, N.Yu., and Tsivadze, A.Yu., J. Porphyrins Phthalocyanines, 2013, vol. 17, nos. 6-7, pp. 564572.

40. Scherz, A., Salomon, Y., Brandis, A., and Scheer, H., US Patent 6569846 B1, 2003.

41. Stuchebryukov, S.D., Selektor, S.L., Silantieva, D.A., and Shokurov, A.V., Prot. Met. Phys. Chem. Surf., 2013, vol. 49, no. 2, pp. 189-197. 